\title{
New Approaches to Model Electric Demand in Aluminium Smelter Industry
}

\author{
A. Molina ", A. Gabaldón ", F. Faura ${ }^{* *}$, J.A. Fuentes ${ }^{*}$ \\ "Department of Electrical Engineering "Department of Materials and Manufacturing \\ $\mathrm{C} / \mathrm{Dr}$ Fleming $\mathrm{S} / \mathrm{N}$ \\ Cartagena, 30202, SPAIN
}

\begin{abstract}
This paper presents and discusses a nonlinear model developed to obtain electrical demand behaviors in a typical Aluminium Smelter Plant. The validation of this model is based on real data measurement for five years of plant activity. The dynamic of the power demand, due to variations of cell parameters electrical or production, has also been considered in this paper. In this way, a sensitivity analysis of the consumption response face to three main parameters has been performed through several simulations, in order to evaluate the suitability of the electrical demand management in this kind of industrial customers.
\end{abstract}

\section{INTRODUCTION}

European countries are involved in a more and more deregulated market for electricity and gas supply. This competition in the electricity market might affect utilities as well as customers. Some users, such as large customers, believe that liberalization means the decrease of utility efforts to affect the amount and timing of customer electricity uses Demand-Side Management, DSM, programs-.

Often these industrial customers have traditionally opposed to such DSM programs because they believe utilities are focused only on improvement of production and delivery costs rather than in electricity services (for example quality of energy). They think that the market is self-efficient and require no utility intervention.

Thus, in a deregulated marketplace, the future of DSM seems questionable, [1]. Perhaps this premise is true, but in this new environment some industry processes allow us to apply not only Conservation, but also Load Management policies, [2]. For example, some industrial chemical processes -as is this case- may be varied between specific technical limits. In other industries the process allows us to delay the start-up of the production, changing and controlling the moment of starting the machinery. Finally, some loads have a certain kind of inertia and may be controlled for some time -this is a case very closed to residential Load Management-. Unfortunately these possibilities have often been ignored and, at this moment, the large industrial customers should be interested in improving their policies for energy management and control, because purchase of electricity will be very similar to other process inputs, and it will become another platform of competition. The evaluation of each option of supply on a comparative basis requires some necessary tools: access to the regional/state database, understanding generation and transmission cost structure, and a thorough understanding of the energy needs of each customer. This way, the knowledge of demand patterns arises as a fundamental tool for end-users

Aluminium Smelter Industry is one of the biggest demands in industrial activities (it accounts for the $1.8 \%$ of the total U.S. industrial energy consumption in 1998, [3]). So, we can identify electrolytics among the four major end uses (motor drives, process heating and lighting). The development of energy efficiency in electric end use technologies for electrolytics can save a large percentage of electric consumption. These methods are for example the use of bipolar cells, inertial anodes and wettable cathodes. Another method to improve the ratio production/energy use is to model the sensitivity of the process versus some production parameters.

On the other hand, the physically-based model we present in this paper for the electrolytic cells of smelter -based on mass, energy balance and chemical kinetics equations- could also be used to solve problems related with the process control. The control of industrial processes is actually being considered as an important type to achieve improvements in industrial plant management. For example, this model should support -integrated into an expert or knowledge-based system - the training of young operators in normal cycles of plant operation. This integration of models and methodologies could improve the plant operational standards and allow the saving of a considerable amount of energy (the primary concern of this paper). At present, energy represents a large share of the cost of primary aluminium production, around 21 percent, giving competitive advantage to producers with access to lower electricity tariffs or with Power Management Systems. In this way, the obtained model is a tool that could be integrated in an Industrial Power Management System to support some typical functions of these tools.

This way, the purpose of this paper is to provide a consistent statement of how demand response works in an aluminium plant and what is the possibility of planning changes in its consumption without having some negative effect in the production or metal quality. To profit the opportunities and to face to competition the users will require tools like this to make decision.

\section{THE ElECTROLYTIC PROCESS. DESCRIPTION}

The aluminium is produced by a sequence of two processes. The first one, the Bayer process, extracts aluminium oxide. 
The second one, the Hall-Héroult process, smelts the aluminium oxide and, by electrolytic reduction, metallic aluminium is finally obtained. The analyzed plant has a rated power of $325 \mathrm{MW}$, supplied from its utility at $410 \mathrm{kV}$. The industry substation has two outputs: Two $20 \mathrm{kV}$ feeders and three $70 \mathrm{kV}$ feeders, supplying power from three transformers to the rectifiers. The lay out of this plant has two series of cells, each one made up of 256 cells, being supplied by four DC sources. Our interest is focused on smelter aluminium production from alumina dissolved in molten criolite, [4]. These are the main ingredients of the electrolyte, however, small amounts of alloying agents are also used in order to obtain the desired properties. So, this chemistry bath is situated in electrolytic cells which are normally connected in series and fed by means of a high DC current - between 150 and $250 \mathrm{kA}$-, being the DC voltage of each cell around $4 \mathrm{~V}$. The theoretical minimum energy consumption in aluminium electrolysis is $6.34 \mathrm{kWh} / \mathrm{kg}$ of $\mathrm{Al}$. Nowadays, the lowest energy consumption that could be achieved is around 13.0 $\mathrm{kWh} / \mathrm{kg}$ of $\mathrm{Al}$ for a line of high amperage alumina reduction cells (i.e. an energy efficiency of about $50 \%$ ). A typical electrolytic cell is basically formed by:

1) Anodes: They can be divided into two groups, Söderberg and prebaked, both formulated from similar materials and being their main difference the anode arrangement. The ingredients used in both instances are petroleum or pith coke and a binding pitch, being their duration normally between 2 and 4 weeks. The polarization of the anodes is one of the most important processes to take into account, since it gives a fairly significant contribution to the overall energy consumption.

2) Bath chemistry: The electrolyte: It typically contains the following concentrations in mass: criolite -75 to $90 \%$, alumina -1 to $8 \%, \mathrm{AlF}_{3}-3$ to $10 \%$ and $\mathrm{CaF}_{2}-5$ to $8 \%$. Each cell design has its own operating requirements and different addition percentages and, therefore it does not exist a general electrolyte composition with fixed concentrations in mass. The main electrochemical reaction in the cell is represented by the following expression, [5]:

$2 \mathrm{Al}_{2} \mathrm{O}_{3}+3 \mathrm{C} \rightarrow 4 \mathrm{Al}+3 \mathrm{CO}_{2}$

3) Cathode: The metal produced in an aluminium smelter just acts as the cathode for the electrochemical reaction. For this reason, the desirable features for a good cathode are: A high electrical conductivity, a low coefficient of expansion and a minimum real surface area. So, the basic design of all cathode linings is to have a steel current collector bars embedded within the carbon to minimize the voltage losses due to the resistance. The construction is completed by a thermal insulating materials. A typical cathode service life being between 1000 and 2000 days.

Fig. 1 shows schematically a typical cell with prebaked anodes, this kind of anodes have the advantage that better compaction and quality control can be maintained, [4].

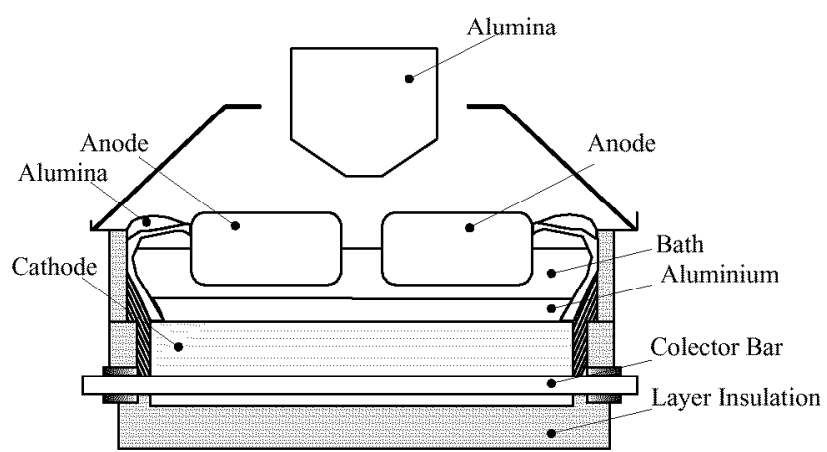

Fig. 1. Example of a prebaked anode cell

In reference to the overall parameters related with this electrolytic process -electrical, chemical, thermal...- it is necessary to take into account that their values are limited to specific ranges. Most of these ranges have been fixed through the experience, and their correlations and relationships are also eminently empirical, [5].

The more efficient utilization of electrical energy has been a halving in energy requirements from $28 \mathrm{kWh}$ per $\mathrm{kg}$ at 1900 to about $13 \mathrm{kWh}$ per $\mathrm{kg}$ today. These improvements have been associated with a greater understanding of the chemical processes and the metal demand. In this way, the total production of aluminium has increased along this century, maintaining a moderate growth during the last two decades.

\section{MODEL DEVELOPMENT}

\section{A. Main Parameters: Nomenclature}

The number of parameters related with this electrolytic process is too wide. For this reason, it is necessary to select the most important and neglect the rest of them in order to analyze the process with enough accuracy and, at the same time, make easier its understanding. With regard to these premises, the selected parameters are the following -their most common ranges are also showed-.

$A l F_{3}$. Excess of $\mathrm{AlF}_{3}$ in $\mathrm{Na}_{3} \mathrm{AlF}_{6}(3-10$ mass $\%$ )

$C A$. Cell Age (0-40 months)

$C C$. Carbon Consumption $(0.4-0.48 \mathrm{~kg} / \mathrm{kg}-\mathrm{Al})$

$C D$. Current Density $\left(0.6-1.2 \mathrm{~A} / \mathrm{cm}^{2}\right)$

$C E$. Current Efficiency. Faradaic Efficiency. (90-95\%). It determines the relationship between the real and the theoretical amount of aluminium, assuming that only aluminium is deposited at the cathode.

$D_{A-C}$. Anode Cathode Distance $(3-7 \mathrm{~cm})$

$E C$. Cell Electric Consumption (13-15 kWh/kg-Al)

$I$. Current (100-250 kA)

$M H$. Metal Height $(20-40 \mathrm{~cm})$

$M P$. Metal Production (1000-1500 Kg-Al per Cell and Day) 
$R R$. Reactivity Residue ( $\mathrm{kg})$. It is only associated with the average weight of anodic residues

$T$. Bath Temperature $\left(940-980^{\circ} \mathrm{C}\right)$

$V$. Cell Voltage (4-5 V)

$V_{A}$. Anode Voltage Drop (0.3-0.4 V)

$V_{B}$. Bath Voltage Drop (1.3-1.8 V)

$V_{C}$. Cathode Voltage Drop (0.25-0.4 V)

$V_{D}$. Decomposition Voltage Drop: It is assumed $1.65 \mathrm{~V}$, constant value for the electrolytic process. In other cases, it has been assumed $1.2 \mathrm{~V}$ as a constant value.

\section{B. Electrolytic Process Modeling}

Taking into account the parameters showed above as well as the main relationships between them - which have been mainly obtained through the experience- a nonlinear equation system has been adjusted from the data collected during several years of a line of 256 cells connected in series. Therefore, a mathematical model of this plant has been obtained which is not too complex, but sufficiently accurate. The whole set of equations is the following:

$$
\begin{aligned}
C C= & 146.6+(284 / C E)-0.15 \cdot R R \\
C D= & 1.385+0.0024 \cdot A l F_{3}-0.0005 \cdot T-0.042 \cdot V \\
E C= & (2.98 \cdot V) / C E \\
C E= & 125.7+0.78 \cdot A l F_{3}-0.03 \cdot T- \\
& -0.45 \cdot M H-42 \cdot V-13.22 \cdot I \\
M P= & 8.06 \cdot I \cdot C E \\
T= & 2859.8-0.15 \cdot D_{A-C}+5.6 \cdot M H-42 \cdot V-13.2 \cdot I \\
V= & 54.1-0.018 \cdot A l F_{3}-0.018 \cdot T- \\
& -51.2 \cdot C D+0.13 \cdot M H \\
V= & V_{A}+V_{B}+V_{D}+V_{C} \\
V_{A}= & 7.1+0.011 \cdot A l F_{3}-0.003 \cdot T-5.29 \cdot C D \\
V_{B}= & 3.6-0.0028 \cdot A l F_{3}-0.0016 \cdot T-0.094 \cdot D{ }_{A-C} \\
V_{C}= & 3.38+0.011 \cdot A l F_{3}-0.017 \cdot T-2.056 \cdot C D
\end{aligned}
$$

As it can be seen above, the system is formed by 11 expressions and 18 parameters. So, it would be necessary to fix seven of these parameters, initially, in order to obtain the values of the rest of them by solving the equation system. Nevertheless, four of these parameters are already fixed, since they depend directly on the state of the smelting aluminium plant. These are: Reactivity residue $(R R)$, bus bar voltage drop $\left(V_{B B}\right)$, decomposition voltage drop $\left(V_{D}\right)$ and cell age $(C A)$-. Therefore, the total number of parameters which has to be fixed, and at the same time will allow us the control of the electrolytic process, is three. However, it is not possible to choose arbitrarily between them, but it is necessary to be able to control them independently and externally to the process.

\section{Validation of the Model}

In order to validate this mathematical model, data collected from another line of cells belonging to the same plant -and with identical constructive characteristics- have been compared with the results obtained from the mathematical model. So, as input variables, the following parameters have been used: Current $(I)$, anode cathode distance $\left(D_{A-C}\right)$ and metal height $(M H)$, The rest of them could be obtained from the mathematical model, for each time period, as output variables.

Fig. 2 shows the percentage differences between measured data and simulated results for each output variable and time period. In all the cases, this difference is less than $7 \%$, which shows the suitability of the model to forecast the parameter yearly evolution as well as their response face to input parameter modifications.

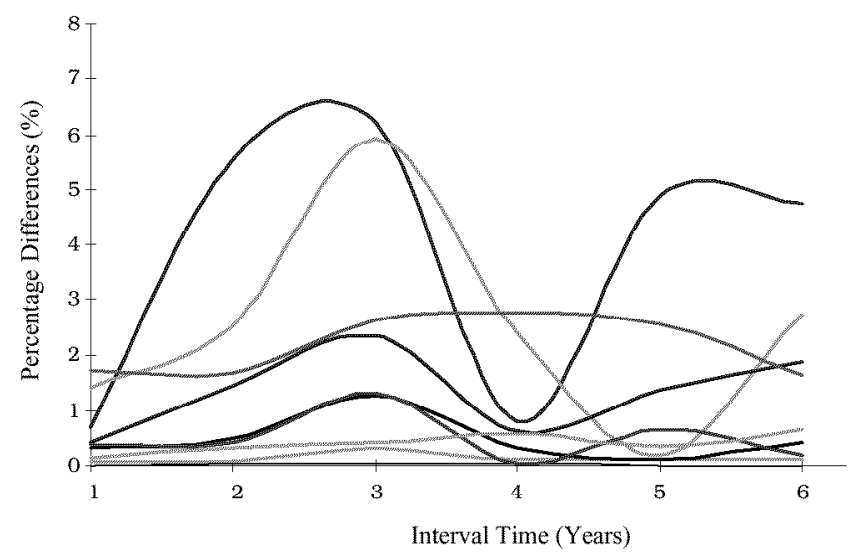

Fig. 2. Percentage differences between real and simulated data

\section{Demand Management. PossibILITIES}

\section{A. Power Management Systems}

Possibilities of Demand and Energy Management should he seen from a global perspective, not only from the utility side but also from the consumer side. From the utility point of view, any policy of Demand Management could be achieved at a lower cost than many supply-side investments. For example, the benefits of Demand Management are well known in Power Planning. One of the fundamental factors affecting the design of Transmission and Distribution Systems, a fact that creates many opportunities for DSM, is that it costs more to upgrade most Transmission and Distribution facilities to a higher capacity than it did to build that capacity in the original design. The possibility of "produce" new energy resources through Efficiency and Energy Management could 
be achieved at a lower cost than supply expansion (this policy is very similar in effects to Distributed Power Generation).

From the customer side, the value and benefits of these management systems are not well understood with exception of energy and demand cost reductions through Time of Use Tarifls (TOU). Recently, many papers [6] have shown the potential benefits of Power Managements Systems. Other benefits such as manpower savings or indirect cost savings (avoiding downtime, improving system production, system reliability or lifetime appliances) can be available to the industrial customers through implementation of some Power Management System functions. We will explain some of these functions and the possible contribution of our model in this goal.

1) Electrical system operations: It reduces operating manpower due to centralized control and allows a better optimization of work practices and procedures. For example, in overload condition or maintenance operation the model could identify the maximun load reduction in each cell series, whereas some appliance is testing in the plant (without additional peak generation and costs) or when a maintenance program is being performed in some substation equipment (transformers, rectifiers,...).

2) Plant analysis: A demand model can evaluate the feasibility and capacity for plant expansion (new cells in the series) with and without additional distribution investments. For example, in some electrical distribution systems in the industry, feeders and transformers are designed overestimating the real loads. A physically-based model - such is the model presented here- can give the plant engineer the necessary information to evaluate the load face to the available capacity, and moreover could forecast more accurately the new loads before plant expansion.

3) Energy cost management in de-regulated Power Systems: The model is a tool that should provide either changes in demand or in energy profile. The profile is a time-based load demand curve necessary to negotiate the best contract with a utility or a power broker under deregulation framework in the utility industry. Nowadays or in the near future, this profile becomes a necessity in Europe and in the United States. Of course, for the industrial customers, this profile would have to be evaluated by their own economical studies and should be consistent with the nature of the productive process.

From the utility side, the main objective is to reduce total transmission and distribution (T\&D) costs. T\&D planners always have a great interest to look at their long-term needs carefully. T\&D facilities are typically built with a considerable growth margin to account for the very high cost per $\mathrm{kW}$ to upgrade or expand $\mathrm{T} \& \mathrm{D}$ system. This fact creates one of the best-perceived opportunities for DSM programs.

Due to these reasons, several DSM programs have been applied by utilities in order to achieve three objectives: improving the system load factor - ratio of average power to the peak power and it is also used as a measure of the effectiveness of load management, [7]-, reducing the demand peaks and shifting the load profiles. In some countries, Time-of-Use (TOU) tariffs is one of the DSM strategies that has widely been applied to industrial customers, [8]. It is based on encouraging the electrical consumption pattern modification by means of altering the cost of electricity during each time period.

Load Shedding, the ability to shed non-critical load or segregate loads to minimize stability problems, is another DSM alternative in order to cut peak demands. Besides, it could be used to reduce utility expansion requirements and improve systems losses and reliability. Fig. 3 shows several residential demand profiles that were collected during the last two years from Spanish residential areas. So, if the utility objective is to improve the system load factor, the industrial load demand would be controlled during the peak-on periods of the residential and commercial sectors, and recovered during their valley periods. This way, from the point of view of the overall system, the maximum peak value could be shaved and the valley periods could be filled.

In our case, an aluminium smelting plant, the global load management seems not to be an alternative because any interruption of energy supply supposes a freezing of the bath that affects the cell lifetime, the rise of energy consumption and distribution losses (after control periods), and a significant drop in the cell metal production. Some research is being performed at present by authors to evaluate this possibility, and we expect to present the results in a future work.

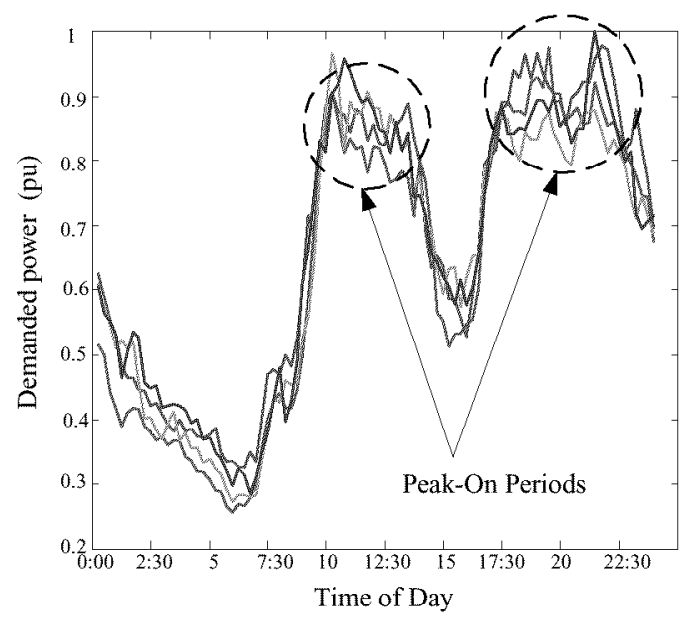

Fig. 3. Residential demand profiles

\section{B. A Case of Study}

To study the suitability of the model to achieve an effective power management, once the mathematical model has been validated, the objective of this section is focused on determining the modification possibilities of the plant power demand, taking into account the performance range of each of the system parametcrs. Therefore, from the adjusted equation system and according to the regulation industrial possibilities, the parameters which have been selected to study this electrical demand management are the same than those 
selected in the previous section -intensity, anode cathode distance and metal height- So, it has been determined the range of allowed power demand values by means of varying these parameters inside theirs suitable value ranges, maintaining the rest of the system parameters without exceeding theirs own limits. The following table shows the main results and the power demand referred to its nominal value.

TABLE I

POWER DEMAND VALUES

\begin{tabular}{|c|c|c|c|c|c|}
\hline $\begin{array}{c}\text { Intensity } \\
\text { (kA) }\end{array}$ & $\begin{array}{c}\text { Cell } \\
\text { Power } \\
\text { (p.u.) }\end{array}$ & $\begin{array}{l}\text { Production } \\
\text { (kg/cell-day) }\end{array}$ & $\begin{array}{l}\text { Cell Electric } \\
\text { Consumption } \\
(\mathrm{kWh} / \mathrm{kg}-\mathrm{Al})\end{array}$ & $\begin{array}{l}\text { Bath Temp. } \\
\text { ('C) }\end{array}$ & $\begin{array}{l}\text { CE } \\
(\%)\end{array}$ \\
\hline 139.5 & 0,991 & 1001.30 & 14.22 & 980 & 89.05 \\
\hline 140 & 0,983 & 1004.0 & 14.07 & 980 & 88.97 \\
\hline 140.5 & 0,975 & 1006.65 & 13.92 & 980 & 88.89 \\
\hline 141 & 0,967 & 1009.29 & 13.77 & 980 & 88.81 \\
\hline 141.5 & 0,962 & 1012.66 & 13.65 & 980 & 88.79 \\
\hline 142 & 0,956 & 1015.44 & 13.53 & 980 & 88.72 \\
\hline
\end{tabular}

According to the previous table, the modification of the power demand is limited around $5 \%$ of its nominal value. This variation is mainly limited by the bath temperature, which only has a allowed value range of $\pm 1 \%$ of its average value. Besides, a decrease in the electrical parameters causes a rise in this temperature, (7), which limits still more the allowed power range. On the other hand, if the metal height or anode cathode distance were decreased in order to maintain the bath temperature inside its range, with a constant intensily, this would produce a rise in the cell voltage and, therefore, a rise in the demanded power. Finally, it could result paradoxical that the power demand increases when the intensity is decreased; nevertheless, this is due to the additional relationships between the cell voltage with the rest of parameters.

Fig. 4 shows graphically the demanded power regulation in relation with the intensity and the anode cathode distance. This results have directly been obtained from the previous table.

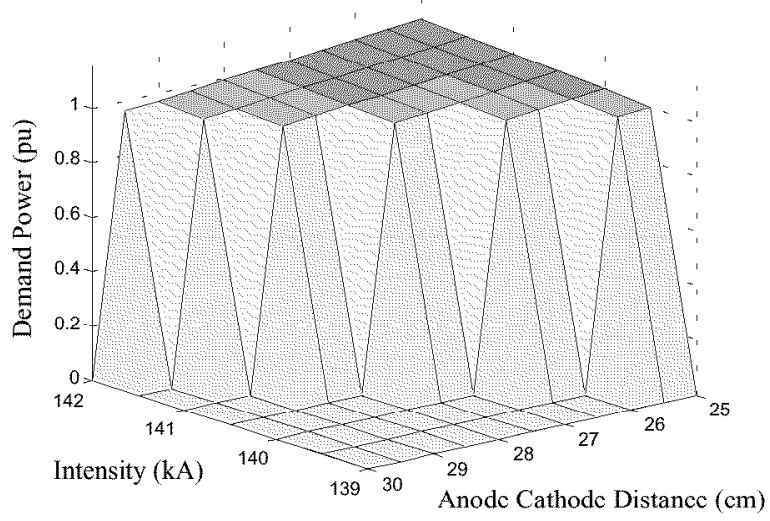

Fig. 4. Demanded Power Regulation
Some authors suggest a larger variation for the bath temperature, [5], which would allow us to decrease the power demand below the minimum value calculated previously. In our case has been used a smaller interval, since it has been taken into account the steady-state evolution of this specific plant as well as other bibliographies in which is suggested a maximum value of $980^{\circ} \mathrm{C}$. Nevertheless, the difference between both minimum power values is not very significant.

Some facts should be appointed in order to precise the results shown in Table I. First, the rise of $1.8 \%$ in DC current increases the load-related losses due to resistance of busbar and impedance of wound equipment (transformers and regulators). Thus, as electrical losses increases as the square of the load (i.e. a $3.6 \%$ ) this implies a demand about $0.5 \%$ higher than the initial global energy demand. Unfortunately, at present we have not found data about plant rectifiers, and so, their losses have not been precisely evaluated. Also, this $3.6 \%$ increment in losses has threc costs: demand (the cost of providing the rise in peak current through busbar and rectifiers to deliver power to cells), the transformer loss of life and the possibility of busbar cracking (with the maintenance cost that this problem implies). Thus process and maintenance engineers should analyze these results (demand and energy reductions) against non-energy costs (maintenance, operation, process...).

Finally, it is necessary to indicate that the level of demanded power should be determined through an optimization process, taking into account the electrical rates and the needed chemical process parameters to achieve a profitable solution from the industrial point of view.

\section{IV.CONCLUSIONS}

This paper presents a new approach to model the electrical demand of an aluminium smelter plant based on a nonlinear equation system. This system allows us to determine the feasibility of improving energy efficiency as well as the demand regulation possibilities in every particular process. The model has been tested from the data collected during several years of a specific aluminium smelter plant. So, it has been obtained its power regulation interval -around 5\%-taking into account the possibilities of variation for each parameter and their nominal value along the plant steady state. The interest of modifying this power demand is focused on analyzing the possibilities to improve the electrical consumption in reference to TOU strategies that have widely been used by utilities as Demand management programs.

These modeling tools have not been considered since a few years ago, but tomorrow they will be of growing importance in a more competitive framework, where the five percent modification achieved theoretically in our simulation will surely have an important economical benefit or at worst this reduction will free up some MW capacity to provide plant growth and competitiveness. 


\section{REFERENCES}

[1] S. Talati and J. Bednarz, "Deregulation and Opportunities for Industrial Customers", IEEE Trans. on Industry Applications, vol. 34, no. 6, Nov. 1998

[2] Curt O. Björk, "Industrial Load Management - Theory, Practice and Simulations", Elsevier, 1989

[3] U.S. Department of Energy. "Energy and Environmental Profile of the U.S. Aluminium Industry", July 1997

[4] K. Grjotheim and B. J. Welch, "Aluminium Smelter Technology", $2^{\text {nd }}$ Edition, Aluminium Verlag,, 1988

[5] T. Drengstig, D. Ljungquist and B. A. Foss, "On the $\mathrm{AlF}_{3}$ and Temperature Control of an Aluminum Electrolysis Cell", IEEE Trans. On Control System Technology, vol. 6, no. 2, March 1998
[6] K.E. Nicholson, R.L. Doughty, L. Mane, G. Miranda and F.D. Pulaski, "Cost Effective Power Management Systems", IEEE Industry Applications Magazine, vol. 6, no.2, March 2000, pp. 23-33.

[7] P. Zalila and A. Asuhaimi, "Electrical Energy Management in Small and Medium Size Industries", IEEE Proceedings of TENCON'93, vol. 5, pp. 379-382

[8] J-N Sheen, C-S Chen and J-K Yang, "Time-of-Use Pricing for Load Management Programs in Taiwan Power Company", IEEE Trans. On Power Systems, vol. 9, no. 1, Feb. 1994, pp. 388-396 